\title{
Gross cardiac involvement in glycogen storage disease type III
}

\author{
Colin G. Miller, George A. Alleyne, and Stanley E. H. Brooks \\ From the Department of Paediatrics, The Tropical Metabolism Research Unit, and \\ The Department of Pathology, University of the West Indies, Kingston, famaica
}

This report describes a patient with type III glycogenosis diagnosed during life but who died suddenly at home and was found at necropsy to have gross cardiac involvement. The immediate cause of death was not apparent but could possibly have been related to the very unusual degree of cardiac involvement.

Involvement of the heart in glycogen storage disease is seen most commonly in types II (Pompe's disease) and III (Cori's or Forbes' disease) (Hohn and Lambert, 1968). In type III glycogenosis, the amount of glycogen deposited in skeletal and cardiac muscle appears to be insufficient to cause functional disturbances; there is only a minimal or moderate decrease in strength and occasionally mild electrocardiographic changes (Pearson, 1968). In contrast, infants suffering from type II glycogenosis die of heart failure or in some instances bronchopneumonia during the first years of life (Hsia, 1968).

We describe here the case history of a 3month-old infant with type III glycogenosis, who died suddenly and was found to have gross cardiac involvement at necropsy.

\section{Case report}

An I I-week-old Negro female infant was admitted to the University Hospital of the West Indies, Kingston, Jamaica, on 9 February 1969, with a history of recurrent fits since the age of $I$ week. She was delivered spontaneously at term with a birthweight of $3.5 \mathrm{~kg}$, and had previously been well. There was no relevant family history. The child had been totally breast fed for six weeks, and then fed mainly on a full-cream dried cow's milk preparation. Her development had been normal and she had never been cyanosed or dyspnoeic.

Physical examination revealed a moderately well-nourished, alert child weighing $5,590 \mathrm{~g}$, with respiratory and pulse rates $76 / \mathrm{min}$ and $144 / \mathrm{min}$, respectively, but there were no other respiratory or cardiovascular abnormalities. The liver was enlarged to $7.5 \mathrm{~cm}$ below the costal margin and was firm, smooth, and non-tender. The spleen and kidneys were not palpable and no central nervous system deficit was elicited.
Urinalysis, a haemogram, lumbar puncture, serum uric acid, and liver function tests were normal. Fasting blood glucose was $27 \mathrm{mg} / 100 \mathrm{ml}$, and a 2-hour postprandial level was $62 \mathrm{mg} / 100 \mathrm{ml}$. Glucagon $\left(0.7 \mathrm{mg} / \mathrm{m}^{2}\right.$ body surface) was given intramuscularly after a 14 -hour fast, and repeated 3 hours after a normal feed but never produced an increase in blood glucose.

An electrocardiogram (Fig. I) showed a short PR interval $(0.08 \mathrm{sec})$ and evidence of biventricular hypertrophy with right ventricular dominance. A chest $x$-ray was normal.

Enzyme studies performed on liver biopsy material revealed evidence of deficiency of the debranching enzyme system (Table). Light and electron microscopy of portions of the liver biopsy provided morphological support for the diagnosis of glycogen storage disease.

The patient's temperature, pulse, and respiratory rates settled to normal within two days. During the glucagon tolerance tests, she was noted to be irritable, but no convulsive episode occurred in spite of severe hypoglycaemia (blood sugar levels of $15 \mathrm{mg} / 100 \mathrm{ml}$ ). She was discharged after 6 weeks. Three-hourly milk feeds, including a late night feed, were advised. The child was seen again 2 weeks later when she was apparently well, weighing $6,590 \mathrm{~g}$, and had had no recurrence of fits. Four weeks later she died suddenly at home.

Necropsy There was an interval of 67 hours between death and necropsy, but the body was refrigerated during this time. The findings were consistent with type III glycogenosis, with involvement of the liver and skeletal muscles. The heart also was strikingly enlarged and weighed $75 \mathrm{~g}$ (twice normal for the age). A transverse section showed gross myocardial thickening with narrow ventricular cavities (Fig. 2). The cardiac muscle was grey-red, with a pronounced glassy appearance. The left ventricular muscle measured $15 \mathrm{~mm}$ in thickness and the right ventricle 6-7 mm. No valvular or endocardial abnormalities 
TABLE Liver glycogen and enzymes

\begin{tabular}{lcc}
\hline & Patient & Normal \\
\hline $\begin{array}{l}\text { Glycogen (mg/g wet } \\
\text { weight) }\end{array}$ & 150 & $50-100$ \\
$\begin{array}{c}\text { Phosphorylase + AMP } \\
(\mu \text { moles/min per g) }\end{array}$ & 18 & $12-33$ \\
$\begin{array}{l}\text { Glucose-6-phosphatase } \\
\quad(\mu \text { moles/min per g) }\end{array}$ & $1 \cdot 0$ & $1 \cdot 2-3 \cdot 0$ \\
$\begin{array}{l}\text { Debranching enzyme } \\
\text { system (glucose from } \\
\text { phosphorylase limit } \\
\text { dextrin } \mu \text { moles/min } \\
\text { per g) }\end{array}$ & 0.0 & $0.3-1 \cdot 7$ \\
\hline
\end{tabular}

were present. There were no congenital anatomical malformations.

Histologically, evidence of stored glycogen was found in the liver, heart, diaphragm, laryngeal muscles, and tongue. The extent of PAS-positive deposits found in these sites was especially noteworthy as the necropsy was done 67 hours after death, and by this time autolysis has usually caused depletion of glycogen in most tissues. The immediate cause of death was not clearly seen, but could possibly have been related to left ventricular outflow tract obstruction.

\section{Discussion}

This is the first proven case of type III glycogenosis to be diagnosed in Jamaica, though a case of generalized glycogenosis, consistent with type III was previously reported (Back and Hill, 1956).

The presence of gross cardiac involvement in type III glycogenosis is unusual. Brown and Brown (I968), in reviewing 34 cases, found that all except 3 patients had survived. Of the 3 deaths, 2 occurred in infancy, and in both cases conspicuous storage in the heart was demonstrated at necropsy. These findings together with those from our case suggest that though most patients with type III glycogenosis run a relatively benign course, death in infancy may occur if the heart is severely involved. The mechanism of death is uncertain, but left ventricular outflow tract obstruction has been demonstrated in 2 out of 3 cases of cardiac glycogenosis, which were catheterized (Hohn and Lambert, I968). Similar haemodynamic complications may well have been present in our case. A sudden increase in obstruction could have led to myocardial ischaemia, ventricular arrhythmia, and sudden death. A hypoglycaemic fit with respiratory obstruction and anoxia could also have been the cause of death, but no signs of an asphyxial death were seen at necropsy.

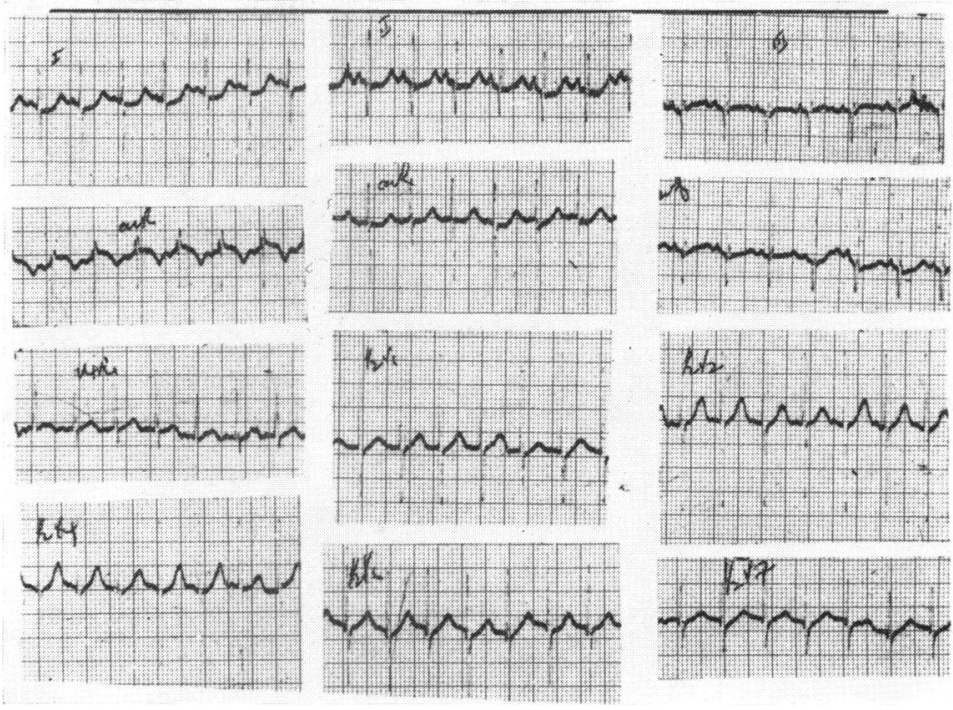

FIG. I Electrocardiogram showing biventricular hypertrophy with right ventricular dominance.

FIG. 2 Photograph of cross-section of heart seen at necropsy, showing gross biventricular hypertrophy.

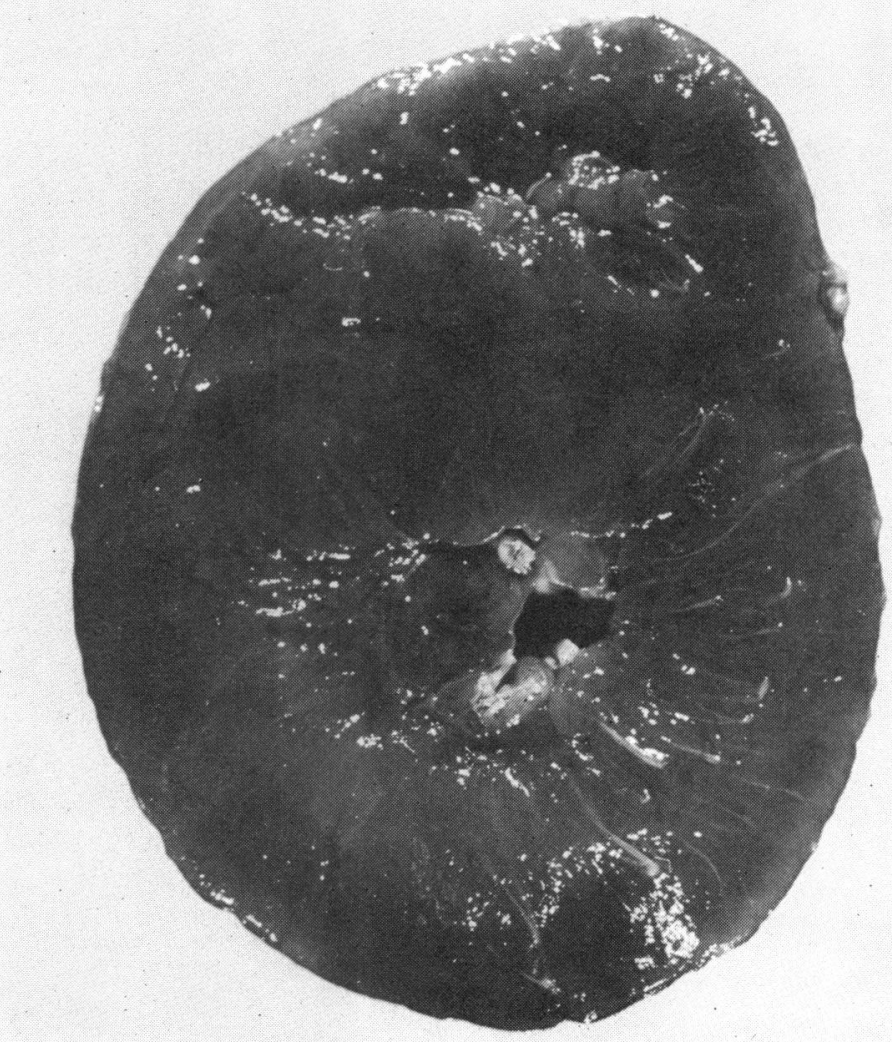


The enzyme assays were performed by Dr. F. Huijing of the Department of Biochemistry, University of Miami, U.S.A.

\section{References}

Back, E. H., and Hill, K. R. (1956). A case of glycogen storage disease in a West Indian infant. West Indian Medical fournal, $5,59$.

Brown, B. I., and Brown, D. H. (1968). Glycogen storage diseases: Types I, III, IV, V, VII and unclassified glycogenoses. In Carbohydrate Metabolism and its Disorders, Vol. 2, pp. 123-150. Ed. by F. Dickens, P. J. Randle, and W. J. Whelan. Academic Press, London and New York.
Hohn, A. R., and Lambert, E. C. (1968). Glycogen storage disease of the heart. In Paediatric Cardio$\log y$, p. 758. Ed. by Hamish Watson. Lloyd-Luke (Medical Books), London.

Hsia, D. Y. (1968). The diagnosis and management of the glycogen storage diseases. American fournal of Clinical Pathology, 50, 44.

Pearson, C. M. (1968). Glycogen metabolism and storage diseases of Types III, IV and V. American fournal of Clinical Pathology, 50, 29.

Requests for reprints to Dr. Colin G. Miller, Department of Paediatrics, University of the West Indies, Mona, Kingston 7, Jamaica, W.I. 